\title{
O processo de reestruturação territorial - produtiva na cidade de Itaguaí- Rio de Janeiro
}

The process of territorial-productive restructuring in Itaguaí-Rio de Janeiro

Le processus de restructuration territoriale et productive à la ville d'Itaguaí-Rio de Janeiro

El proceso de reestructuración territorial - productiva en la ciudad de Itaguaí Rio de Janeiro

\section{Guilherme Mapelli Chagas}

\section{(2) OpenEdition}

\section{Journals}

\section{Edição electrónica}

URL: http://journals.openedition.org/espacoeconomia/1898

DOI: 10.4000/espacoeconomia.1898

ISSN: 2317-7837

\section{Editora}

Núcleo de Pesquisa Espaço \& Economia

\section{Refêrencia eletrónica}

Guilherme Mapelli Chagas, « O processo de reestruturação territorial - produtiva na cidade de ItaguaíRio de Janeiro », Espaço e Economia [Online], 7 | 2015, posto online no dia 12 abril 2016, consultado o 02 maio 2019. URL : http://journals.openedition.org/espacoeconomia/1898 ; DOI : 10.4000/ espacoeconomia.1898

Este documento foi criado de forma automática no dia 2 Maio 2019.

(C) NUPEE 


\section{O processo de reestruturação territorial - produtiva na cidade de Itaguaí- Rio de Janeiro}

The process of territorial-productive restructuring in Itaguai-Rio de Janeiro

Le processus de restructuration territoriale et productive à la ville d'Itaguaí-Rio de Janeiro

El proceso de reestructuración territorial - productiva en la ciudad de Itaguaí Rio de Janeiro

\section{Guilherme Mapelli Chagas}

\section{NOTA DO EDITOR}

O texto em tela resulta da monografia apresentada no Departamento de Geociências/ UFRRJ intitulada“ "O Processo de Reestruturação Territorial-Produtiva no Extremo Oeste Metropolitano Fluminense: 0 caso de Itaguai", bem como também de discussões levantadas no LAGEPPE - Laboratório de Geografia Econômica e Política e Práticas Educativas [DEGEO / UFRRJ] no âmbito do projeto "O Processo de Reestruturação Territorial-Produtiva no Oeste Metropolitano Fluminense", desenvolvido com o apoio da Fundação Carlos Chagas Filho de Amparo à Pesquisa do Estado do Rio de Janeiro - FAPERJ. Da mesma maneira, este estudo é integrante do projeto de cooperação internacional, no campo da geografia, entre a UFRRJ e a Universidade do Porto, intitulado "Reestruturação Espacial e Desenvolvimento Regional: Um Estudo Comparativo entre a Região Norte de Portugal e o Estado do Rio de Janeiro". 


\section{Introdução}

1 A cidade de Itaguaí, contígua à cidade do Rio de Janeiro em sentido oeste, apresenta grande facilidade no quesito infraestrutura produtiva e disponibilidade de terrenos adequados para a instalação de atividades de caráter produtivas. Não é por outro motivo que atualmente esta cidade, bem como toda a região, tem se configurado como um polo de desenvolvimento econômico, devido principalmente às atuais implantações de indústrias em seus limites [e no bairro de Santa Cruz] e por ser sede do Porto de Itaguaí (antigo Sepetiba), responsável pelo escoamento da produção de grande parte do estado do Rio de Janeiro. Itaguaí é vista como um atual palco de inúmeros impactos sócio-espaciais e mudanças urbanas produtivas.

2 As vantagens potenciais de Itaguaí e de seu entorno podem se ampliar e até mesmo se concretizar em um conjunto articulado de empresas que almejam a consolidação de empreendimentos do ramo metal-siderúrgico e logístico-petrolífero, aproveitando a especialização produtiva das empresas já localizadas. A partir disso estão ocorrendo modificações em toda a sua estrutura econômica e espacial, havendo assim uma reestruturação tanto no que diz respeito a produção como ao que se refere ao território. Itaguaí vem se tornando como um "ímã" de atração, no que se trata de novos investimentos; os implica em uma atração populacional em busca da oferta de empregos, modificando assim o cenário urbano deste município e necessitando de novas formas de serviços para suprir as necessidades tanto das indústrias quanto da população.

Portanto, mediante a consolidação de um novo cenário representado por investimentos recentes, a "enxurrada" de capitais que tem sido destinado à cidade de Itaguaí - ainda que o momento político presente tenha refreado alguns aportes do Estado no campo produtivo -, torna-se interessante definir as mudanças espaciais na estrutura urbana deste município, verificando a formação de novos espaços, tanto das novas marcas que estão sendo consolidadas nesta região quanto se a explosão de investimentos industriais tem trazido mudanças no se refere a seu quadro social.

\section{Transformações econômico-espaciais na cidade de Itaguaí}

4 Antes de tudo, torna-se interessante considerar que Itaguaí busca não se legitimar como pertencente à região da Baixada Fluminense devido esta apresentar uma imagem "negativa" e apostando nas diferenças entre seu território e o da Baixada; neste sentido, Itaguaí tenta se afirmar como a "cidade do porto", como uma "cidade inteligente", que apresenta grandes oportunidades de desenvolvimento, como uma cidade que caminha para o moderno e que se encontra mais articulada tanto com a Região Metropolitana Fluminense quanto com a região turística da Costa Verde, procurando se desvincular totalmente dos aspectos negativos de representatividade que caracterizam a Baixada.

5 Itaguaí assiste atualmente a uma explosão de investimentos industriais sendo estes impulsionados pela consolidação de empreendimentos pertencentes ao ramo metalsiderúrgico e logístico-petrolífero, como exemplos de empresas, podem ser citadas: a Companhia Siderúrgica do Atlântico (TKCSA), do grupo transnacional Tyssen Krupp, da Gerdau, Usiminas, contando-se também com a Petrobrás e da LLX, do ramo logístico e que 
pertence a holding EBX, esta que apresenta negócios nos segmentos ligados a exploração de petróleo e gás natural, construção naval, serviços, offshore, mineração, entre outros, estas que já aportaram na região com cerca de $\mathrm{R} \$ 38$ bilhões em investimentos, tendo também como grande relevância a expansão do Porto de Itaguaí (este atendendo individualmente empresas e também a marinha do Brasil). A seguir, pode-se verificar uma imagem (Figura 1) que explicita como se estrutura territorialmente a consolidação dos segmentos industriais na região de estudo, sendo perceptível identificar algumas empresas já retratadas anteriormente e que representam novos investimentos, como também antigas bases produtivas, como a NUCLEP, por exemplo, sendo notável também o Distrito Industrial de Santa Cruz e o traçado do Arco Rodoviário Metropolitano.

\section{Figura1: Complexo Portuário e Industrial da Baía de Sepetiba - Itaguaí}

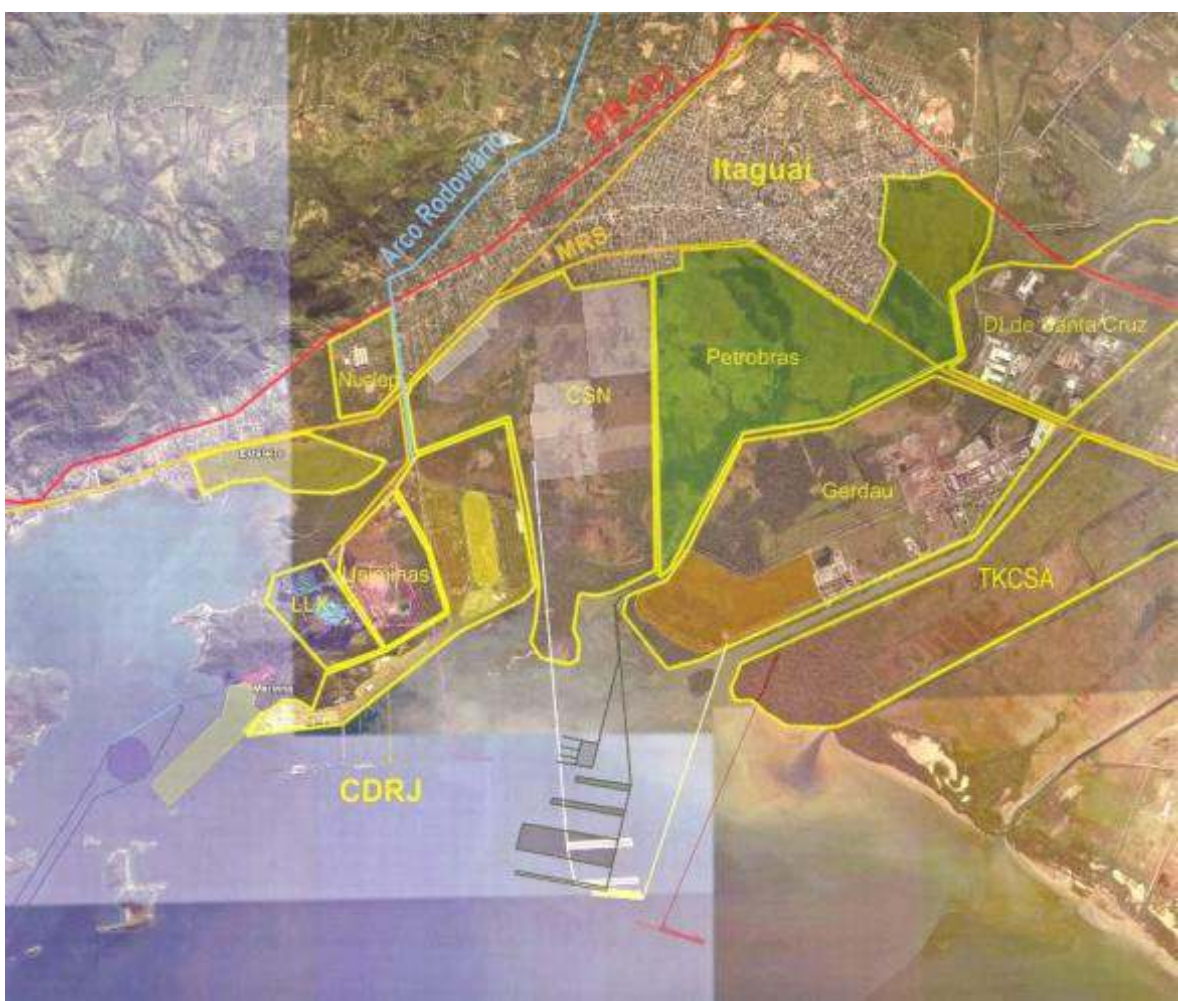

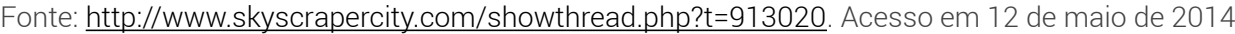

As vantagens da implementação dessas empresas na área do distrito industrial de Santa Cruz e no Município de Itaguaí estão relacionadas com a grande área disponível, a infraestrutura destinada para essas instalações, a logística e o menor tempo de implantação do projeto tendo em vista um menor custo operacional e também dos incentivos fiscais oferecidos pelo Governo do Estado do Rio de Janeiro. Além disso, há a grande vantagem que se tem com o escoamento da produção, fato este por estar próxima à Rio- Santos, cortada pelo ramal ferroviário de Mangaratiba e com acesso ao mar através do Porto de Itaguaí; tudo isto deve ser acrescido pelo advento do Arco Rodoviário Metropolitano, sendo este um projeto da década de 70, mas que somente no ano de 2008, após ser incluído no Programa de Aceleração do Crescimento (PAC), começou a ser construído. $\mathrm{O}$ Arco Metropolitano recebeu grandes investimentos do governo federal e estadual, com valores inicialmente previstos que somaram $\mathrm{R} \$ 1,9$ bilhão; tal via almeja aproximar realidades industriais na borda metropolitana fluminense, sendo idealizada 
como facilitadora do acesso ao Porto de Itaguaí, com o intuito também de diminuir os gastos referentes ao escoamento da produção.

7 A partir deste fato, o Porto de Itaguaí terá uma ligação com as principais vias de acesso interestadual que cortam o estado do Rio de Janeiro, tendo assim uma maior facilidade de conexão com outras áreas do estado. Uma das consequências da implantação do Arco Rodoviário Metropolitano será o de ampliar o acesso ao Porto de Itaguaí, fazendo com que desta forma ocorra um processo de expansão urbana e viabilizando para que haja a instalação de novos empreeendimentos, não apenas nesta cidade como também nos demais municípios "cortados" por esta via. $\mathrm{O}$ arco rodoviário incorpora desta maneira áreas rurais à dinâmica urbana, sabendo-se que ao longo do arco serão definidos espaços destinados ao uso industrial e logístico. Ao se tratar do arco, não vale esquecer, de um fortalecimento metropolitano no que se refere à ótica logístico-produtiva, não sendo possível mensurar as oportunidades sociais oriundas desta nova composição metropolitana.

8 Para entender todas essas modificações que tem ocorrido no município de Itaguaí, tornase necessário salientar a respeito dos mecanismos globais que determinam novas formas de se produzir e da articulação produtiva, tendo em vista que essas mudanças ocorrem provocadas tendo como base principal o processo de industrialização, que ocorre quando o país elege a indústria como sendo o principal motor de sua economia, ou seja, é quando a indústria se torna o setor dominante da economia, fazendo com que se tenha o aumento da produtividade, gerando assim lucros (OLIVEIRA, 2011). Segundo Leandro Oliveira (2011), a industrialização é vista como um projeto hegemônico no qual a produção fabril se torna como dominante sobre as demais atividades existentes e a partir disso passa a exercer influência direta sobre todas as esferas da sociedade, envolvendo desde a política e a economia, até a organização social.

9 Esse processo de industrialização que se insere na área de estudo e é visto como um elemento responsável pelo processo de reestruturação territorial-produtiva; ou seja, como um condutor das transformações, que tem como consequência a consolidação de novas formas e marcas no espaço e se baseia em novos segmentos produtivos e na implantação de novas tecnologias. Esse processo atual implica em novas territorializações, ou seja, formando novos territórios destinados às indústrias, valorizando as áreas ditas "vazias" (desvalorizadas historicamente e pouco povoadas), deslocando o setor industrial do núcleo metropolitano, tecendo assim uma nova relação entre a capital e as demais regiões fluminenses e possibilitando uma maior integração de todo o território fluminense.

10 Tanto Itaguaí quanto o bairro de Santa Cruz são exemplos claros desse deslocamento progressivo das atividades para fora do núcleo metropolitano strictu sensu, sendo baseadas em uma estratégia do uso do território por parte do capital, onde ocorre uma formação de uma nova espacialidade industrial, sendo essas áreas da cidade do Rio de Janeiro as representantes - junto à região da Baixada Fluminense - desse novo cenário industrial, determinado por uma desconcentração espacial, pela consolidação de um novo padrão de localização das indústrias. 


\section{O Processo de Reestruturação Territorial-Produtiva}

11 A partir do que já foi tratado anteriormente, tendo em vista a atuais modificações urbanoprodutivas que acometem a região de estudo e sabendo-se que a industrialização é responsável pelo processo de reestruturação produtiva, torna-se importante aqui definir melhor o que vem a ser esse processo e retratar brevemente sobre a sua origem e suas consequências.

O processo de reestruturação produtiva teve a sua origem nos anos de 1970, mas só começou a ganhar força no Brasil nos anos 1990, com a política do neoliberalismo e a abertura econômica, levando as empresas a buscarem inovações mais efetivas, estratégias de produtividade e qualidade para fazer frente à concorrência internacional. A partir disso houve transformações no processo produtivo, na forma de se produzir, na gestão, na organização do trabalho, no espaço, sendo este processo o responsável por produzir "novos espaços industriais", como também reformular e readaptar antigas bases produtivas.

13 Antes de tudo, deve-se saber que junto ao termo reestruturação produtiva, será incorporado "territorial", oferecendo à ciência geográfica novos ingredientes para se tratar deste assunto (OLIVEIRA, 2015). "Reestruturação produtiva" - termo já discutido em diversas outras áreas do conhecimento como economia, sociologia, engenharia de produção, entre outras - parece remeter diretamente às mudanças que ocorrem dentro da fábrica; ao acrescer-se o termo "territorial" amplia-se a capacidade de analisar espectralmente o processo que ocorre fora da empresa, analisando as consequências e o que está acontecendo no espaço urbano em volta das indústrias, às modificações no que se trata ao espaço urbano, na produção desse espaço, na reestruturação espacial da região que vem recebendo investimentos industriais, como é o caso da cidade de Itaguaí. Cabe, portanto, à geografia analisar os impactos provocados pelo processo de reestruturação na dinâmica espacial, buscando retratar como esse processo se manifesta no espaço e como é que se dá a formação de "novos espaços industriais" (SCOTT, 1988 apud HARVEY, 1992), de novos espaços produtivos, verificando qual o reflexo disso na sociedade e quais as marcas territoriais provocadas por esse processo.

14 O sentido da palavra reestruturação [enquanto substantivo] é "reformular em novas bases estruturais"; "reorganizar"; o "ato ou efeito de reestruturar, ou seja, nova estruturação" (DICIONÁRIO ELETRÔNICO HOUAISS apud SERAFIM-GOMES, 2011, p. 53). Lencioni (1998, p.7-8) considera a reestruturação como movimento, pois:

cabe lembrar que as formas anteriores não se dissolvem nesse processo de reestruturação, elas se modificam e são modificadas pela teia de relações em movimento. Tornam-se, sim, subordinadas face ao desenvolvimento dessas novas formas que reestruturam tanto a sociedade como o espaço.

Sobre a instabilidade das estruturas, Lencioni $(1998$, p. 7) acrescenta:

as estruturas, nem são fixas e nem estáveis. Elas têm um equilíbrio provisório e quando esse equilíbrio é abalado pode ocorrer uma desestruturação-reestruturação, que se gesta no seio da própria estrutura, pois esta tem uma dinâmica que não só a constitui, mas que, também, busca romper os equilíbrios provisórios. Portanto, estruturação-desestruturação-reestruturação se constitui num único movimento.

16 Já Gottdiener (1993) considera a reestruturação como "fenômeno socioespacial", ou seja, como resultado de mudanças sociais e espaciais. Assim, pode-se dizer que o processo de 
reestruturação ocorre quando as estruturas vigentes não conseguem mais atender as necessidades do capital. A partir disso, acredita-se que o processo de reestruturação produtiva passa a ser considerado como uma resposta às crises do capital; isto é, reestruturar seria uma alternativa de modificação na estrutura da forma de se produzir com o objetivo de sair da crise. Segundo Mandel (1982 apud SERAFIM-GOMES, 2011, p. 55), "a reestruturação acontece como mecanismo de superação das crises do modo de produção capitalista".

O processo de reestruturação produtiva corresponde às transformações responsáveis pela modificação da estrutura produtiva da indústria, podendo estas ser na técnica ou no trabalho - assim como entendemos, também na lógica espacial. É um complexo sistema baseado em mudanças na base tecnológica, no setor organizacional, social e espacial da empresa. Esse processo é algo totalmente dinâmico, um processo dialético, onde tanto elementos do "novo" e do "velho" passam a conviver juntos na mesma empresa. Ou seja, a partir disso, pode-se dizer que quando ocorre esse processo, não significa que acontece uma ruptura total da estrutura anterior devido à entrada de um novo sistema, pois ambos os elementos passam a coexistir e como afirmação a esse fato pode-se exemplificar que as empresas industriais que se submetem ao processo de reestruturação apresentam características tanto tradicionais (fordistas) quanto modernas (flexíveis) (SERAFIMGOMES, 2011, p. 56, e, evidentemente, HARVEY, 1989).

18 A implantação dos investimentos industriais na região de Itaguaí tem atuado como responsáveis pela formação de uma nova configuração espacial no que se trata ao espaço urbano, ou seja, pela concretização do processo de reestruturação territorial-produtiva neste recorte espacial, sendo esse processo de reestruturação territorial-produtiva em curso é caracterizado de um lado como uma inovação de caráter tecnológico e organizacional dentro das empresas, e de outro como mudanças espaciais profundas que provocam forte marca geográficas, marcas no espaço da região, responsáveis pela modificação da estrutura do urbano, como por exemplo, fomentando a instalação de novos empreendimentos imobiliários e de uma consequente valorização no que se trata ao solo urbano. Mediante a isso, tem- se que esse processo de reestruturação é responsável por colocar áreas desvalorizadas historicamente no processo de valorização do capital.

19 A reestruturação territorial-produtiva que vem ocorrendo em Itaguaí e em seu entorno implicam, assim, em novas relações de poder e nas novas espacializações econômicas e sociais. Seu caráter produtivo encontra-se pelo fato de estar baseada em um novo modelo econômico denominado de pós- fordismo ou acumulação flexível, que se difere da rigidez do fordismo que era muito dependente de equipamentos com níveis limitados de recursos tecnológicos e apresenta como finalidade de organização, a de suprir a sua demanda colocada no momento exato (just-in-time), atendendo desta forma um mercado diferenciado, que está preenchido por públicos cada vez mais específicos. Nesse tipo de organização, os produtos são somente fabricados ou entregues a tempo de serem comercializados ou montados, permitindo-se assim que a indústria acompanhe as rápidas transformações que ocorrem com os padrões de consumo. Esse novo sistema atua de maneira flexível, em uma nova estrutura da indústria, esta mais descentralizada, e se baseia em um novo modelo apresentando um maior dinamismo no que se refere ao setor produtivo e também dos novos padrões atuantes na organização da produção. Este modelo produtivo emergente, que podemos denominar acumulação flexível, possui características comuns ao Fordismo, mas desconstruiu o antigo padrão de grandes 
plantas, de cidades operárias, de desenvolvimento nacionalista e de produção em larga escala e em série (OLIVEIRA, 2006).

\section{Novos investimentos no ensino e na capacidade técnico-instrucional}

20 A partir dos investimentos industriais que estão sendo inseridos em Itaguaí, é possível identificar a importância desse desenvolvimento para essa região, assim como para toda a cidade do Rio de Janeiro. Itaguaí é um município que sempre sofreu grandes problemas de segregação socioespacial e que tem se tornado um importante lócus econômico, atraindo cada vez mais investimentos estimulados particularmente pelo Governo do Estado do Rio de Janeiro por meio de incentivos fiscais.

21 Com o intuito de atender a necessidade de uma mão-de-obra minimamente qualificada para o mercado local, foi implantada em Itaguaí uma unidade do Centro Federal de Educação Tecnológica Celso Suckow de Fonseca (CEFET), sendo esta ideia fruto de uma parceria entre o Governo Federal com a Prefeitura de Itaguaí e a Empresa Vale. Esta unidade oferece cursos voltados para a área de técnico em mecânica, técnico em porto $\mathrm{e}$ engenharia industrial. A escola tem atuado de forma a aproveitar o potencial de desenvolvimento da região e a proximidade com Arranjos Produtivos Locais, estando aberta a possibilidade de novas parcerias para dar conta das demandas existentes na região. Além do CEFET, tem-se também em Itaguaí o Serviço Nacional de Aprendizagem Industrial (SENAI), que oferece mais de dez cursos direcionados para jovens entre 14 e 24 anos com o objetivo de atender as indústrias e empresas que se instalam na região, oferecendo laboratórios de automação e de instrumentação industrial totalmente equipado e automatizado, favorecendo assim a intimidade do futuro profissional com o seu instrumento de trabalho.

Além do CEFET, na região possui a própria "Escola de Fábrica" mantida pela Nuclep nas dependências da própria empresa e sendo destinada a educação profissional de jovens que pretendem ser inseridos no mercado de trabalho no ramo tecnológico, atendendo assim as demandas da própria empresa. Além destas, podem ser citadas os polos universitários, sendo estes centros de qualificação de mão-de-obra localizados no entorno da região em desenvolvimento, como a Universidade Estácio de Sá presente no bairro de Santa Cruz e que tem oferecido diversos cursos voltados para atender a demanda da região, como engenharias com especializações diversificadas, petróleo e gás, entre outros. Não há como não considerar também a Universidade Federal Rural do Rio de Janeiro (UFRRJ) localizada no município de Seropédica, assim como a Universidade Estadual da Zona Oeste (UEZO), no bairro de Campo Grande.

Outro exemplo de investimento que foi implantado em março do ano de 2014 foi à instalação de um Centro Vocacional Tecnológico (CVT), que será coordenado pela Fundação de Apoio à Escola Técnica (FAETEC), estando localizado no Município de Seropédica, mais precisamente no entroncamento da BR-465, no KM 42, como a Rodovia RJ 099, conhecida como Reta de Piranema, no bairro Vera Cruz. A unidade terá capacidade para formar 2.500 profissionais por ano em cursos voltados em diversas áreas. Os cursos oferecidos serão os seguintes: Operador de Computador; Montador e reparador de Computadores; Auxiliar em Administração de Redes, Pedreiro de Alvenaria; Pintor de Obras; Aplicador de Revestimento Cerâmico; Carpinteiro de Obras; Instalador de 
Tubulações Industriais; Eletricista Instalador Predial de Baixa Tensão; Assistente de Operações Logísticas; Operador de Empilhadeira; Almoxarife (Operador de Estoque e Armazenagem); e Assistente Administrativo de Compras; Auxiliar de Administrador; Auxiliar de Pessoal; Recepcionista; Auxiliar de Recursos Humanos e Técnicos em Logística, ou seja, cursos baseados na Construção Civil, Informática e na Gestão de Negócio e Logística. A implantação deste CVT tem como objetivo alçar a educação profissionalizante na região e adjacências, garantindo desta forma a oferta de uma mão-de-obra qualificada e empregabilidade para a população. Esta unidade foi construída numa área de mais de $2.182 \mathrm{~m}^{2}$, em um terreno cedido pela Universidade Federal Rural do Rio de Janeiro (UFRRJ), com investimento de R\$ 4,1 milhões, sua infraestrutura apresenta salas e laboratórios modernizados, além da presença de oficinas de desenvolvimento científico e tecnológico.

24 Além dessas tentativas de promover o desenvolvimento instrucional-profissional da região, foi verificada também a existência do Programa Empreender, sendo este de iniciativa de âmbito nacional, que une a Confederação das Associações Comerciais e Empresarias do Brasil e o SEBRAE (Serviço Brasileiro de Apoio às Micro e Pequenas Empresas), e que foi implantado na região com a Federação das Associações Comerciais e Empresariais do Estado do Rio de Janeiro (FACERJ) e a Associação Comercial, Industrial e Agropastorial de Itaguaí (ACIAPI). Esta ideia surgiu com o objetivo de fortalecer micro e pequenos negócios na região, promovendo assim o desenvolvimento dos pequenos empresários através de capacitação e também havendo uma troca de informações entre eles. Desta forma, é importante o incentivo ao mercado local, para que a renda gerada pelos empreendimentos instalados e desenvolvidos por este programa seja absorvida pela economia da região. A partir destes exemplos é que se verifica como está sendo em parte resolvida a questão da necessidade de desenvolvimento de infraestrutura para atender as demandas desses investimentos na região, sabendo-se que estes necessitam de um acompanhamento de grandes planejamentos, pois podem gerar um crescimento de forma desordenada.

\section{Uma nova geografia econômio-industrial da cidade}

Itaguaí retrata bem a imagem representativa de um vetor de expansão que se encaixa em um novo modelo de Geografia da Indústria do estado do Rio de Janeiro, em uma nova cartografia fabril fluminense, esta que se dá baseada em uma nova forma de estruturação territorial, que promove um desenvolvimento de "industrialização de borda" que visa promover de forma estratégica o processo de industrialização na borda metropolitana, fugindo do centro, desconcentrando industrialmente o seu núcleo e atraindo as atividades fabris para outros espaços, promovendo a produção de novos espaços e criando para isso infraestruturas necessárias para melhor gerenciamento de tais investimentos - como o já relatado Arco Rodoviário Metropolitano, este que pretende atuar como articulador e integrador de todo o território fluminense sendo responsável por ser a espécie de "veia articuladora do desenvolvimento" do estado.

A cidade de Itaguaí é o exemplo claro de como o processo de reestruturação territorialprodutiva que acomete a região tende a influir na formação de uma nova dinâmica espacial, de mudanças na estrutura urbano-produtiva, criando novos locais, novas formas e funções para o espaço, tencionando para que a produção do espaço ocorra no afã de atender as suas necessidades, os interesses vigentes, propulsando a criação de 
infraestruturas para alimentar a esteira do seu desenvolvimento. Ou seja, a cidade procura se configurar de acordo com as demandas necessárias, criando instrumentos, novos elementos, infraestruturas adequadas para receber, ser palco de tais investimentos. A cidade se reestrutura, de forma simples pode-se dizer que ela molda a sua estrutura "vestindo uma nova roupagem".

Em relação às mudanças econômico-espaciais contemporâneas que tem se configurado em Itaguaí, tem-se que estas podem ser observadas de acordo com diversas alterações observadas na estrutura da cidade após esta se tornar como alvo de novos investimentos, de um olhar mais atrativo ao capital. De acordo com essas modificações na estrutura urbana da cidade, dois pontos interessantes devem ser considerados: a especulação imobiliária, que se relaciona com uma valorização do solo urbano como também o que diz respeito à configuração da cidade em si, de como esta se configura; e de como se encontra a questão de sua infraestrutura urbana, das ações por parte do poder público em criar novos serviços, e também em promover seu desenvolvimento social.

Ao tratar sobre como a cidade de Itaguaí se promove as custa de seu desenvolvimento econômico, mas com apartado desenvolvimento social, chega a ser intrigante pensar, como uma cidade, que se retrata como a "cidade do porto", como uma "cidade inteligente", tem, na verdade, se apresentado ainda com problemas característicos de cidades que tiveram um crescimento acelerado e desorganizado, tendo uma urbanização periférica e sem um respectivo planejamento por parte de interesses públicos visando um desenvolvimento social, uma melhoria na qualidade de vida e de serviços prestados a sua população, como saúde, transporte, educação, saneamento básico, entre outros. Mas o que realmente se configura é toda uma propaganda entorno das possibilidades de desenvolvimento - em uma verdadeira "ideologia do desenvolvimento" extemporânea que gira em torno de pseudo-possibilidades, de potencialidades da região, de aumento nos postos de trabalho devido à chegada de novos investimentos, que a cidade encontra-se numa rota do crescimento, que só tende a se desenvolver, que apresenta aspectos favoráveis para morar, trabalhar e investir. Porém, na verdade, este desenvolvimento não reverbera em grandes avanços no que se refere a seu quadro social e procura de certo modo mascarar toda a problemática que tende a surgir em seu território, como os conflitos culturais, sociais, ambientais.

A partir da chegada dos investimentos industriais na região a cidade se modifica, se transforma constantemente visando atender suas necessidades, pois com a chegada dos investimentos há o estímulo para a produção do espaço e ao mesmo tempo a necessidade para que ocorra o desenvolvimento de serviços voltados para a ocupação urbana. Há como exigência se criar essa infraestrutura, com a formação de uma nova dimensão da ocupação e da própria malha urbana.

30 Mediante isso, emergem muitas dúvidas a respeito de como a cidade de Itaguaí irá se configurar, de como estará daqui a cinco, dez ou quinze anos, devido a rápida alteração em sua estrutura, que tanto pode trazer novas possibilidades, oportunidades de desenvolvimento para a região como também agravar os problemas já existentes e surgirem novos oriundos do seu acelerado crescimento. É a partir desse apontamento então, que se deve privilegiar, no presente, a instituição de estratégias de planejamento para lidar com os novos desafios, com as novas problemáticas como também gerenciar de modo mais proveitoso as potencialidades surgidas na região, tratando da teia de elementos inseridos no processo de desenvolvimento urbano, por meio de incentivo por parte de políticas públicas para mediar os conflitos criados, os impactos, as mudanças que 
tem se configurado na estrutura da cidade e que tem provocado à consolidação de uma nova geografia urbana e industrial no município, uma "Nova Itaguaí" que está nascendo, se formando.

\section{Considerações finais}

31 O processo de reestruturação territorial-produtiva que vem ocorrendo em Itaguaí e em seu entorno implicam, como já retratado, em novas relações de poder e em novas espacializações econômicas e sociais e na configuração de impactos ambientais, culturais, sociais, de certo modo mascarados pela manifestação positiva referente às possibilidades e potencialidades da região em relação a seu desenvolvimento.

Tendo em vista todo o processo de reestruturação territorial-produtiva que acomete a região de estudo e as teias de relações que são constituídas no meio dele, este processo é visto como um instrumento fundamental para a solidez do sistema capitalista, este que atua de modo estratégico na produção do espaço, visando, claro, produzi-lo, projeta-lo com objetivos específicos, de modo a atender a seus interesses e necessidades. 0 espaço é visto de modo estratégico, dotado de intencionalidades e sentidos, adquirindo assim, novas formas, conteúdos, significados. Ao considerar o espaço como sendo o lugar onde se desenvolve as relações capitalistas de reprodução, tem- se que a partir disso há uma série de manifestações relativas à formação de conflitos, lutas e contradições que nele se reproduzem.

Itaguaí é um exemplo claro de uma mudança territorial baseada em uma estratégia de uso de territórios por parte do capital. Ao analisar todo esse processo que se desenvolve em Itaguaí, é perceptível compreender como o sistema capitalista produz o espaço, de como este é visto cada vez mais como uma mercadoria, como um meio de produção e de como essa produção se dá de maneira desigual espacialmente, pois se há locais como Itaguaí, considerados como um "ímã" de atração de investimentos, onde há injeção de capital constante, também há outros onde se caracterizam por ser um "espaço de escassez", de pobreza, esquecidos, isolados e que não apresenta no momento um caráter atrativo a interesses econômicos.

Em relação a isso, tem-se também que o capital apresenta um caráter de migração, mobilidade e de flexibilidade impressionantes, pois, se hoje ele injeta recursos econômicos em uma região como esta acontecendo em Itaguaí, amanhã, isso pode se alterar, pois uma nova região pode vir a se tornar mais atrativa para ele, realizando assim uma nova concentração de capital. Não é por outro motivo que se pode dizer que o futuro, tanto de Itaguaí como de qualquer local que tem sido marcadamente inserido na ótica de investimentos de capitais é imprevisível, e é a partir desta lógica de incertezas de um mundo marcado por um tempo de produção e consumos acelerados e em plena mudança, com renovação de valores e sentidos, criados pelo capital e influenciados por atores hegemônicos diferenciados, é que não se sabe como esta cidade se encontrará daqui a cinco, dez ou quinze anos, tanto no que se refere se ainda se inserirá em um quadro atrativo da atuação do olhar do capital. Afinal, como a cidade se configurará mediante as transformações atuais em sua estrutura? Qual o possível legado baseado nas sinergias geradas pelo seu desenvolvimento econômico? Quais os impactos deste crescimento econômico em seu desenvolvimento social? Itaguaí tanto poderá surgir como um lócus de novas possibilidades de desenvolvimento como também não suportar os impactos, agravando os problemas já 
existentes e fazendo com que surjam novos oriundos do seu acelerado processo de crescimento.

Apesar de toda problemática instaurada pela via do seu desenvolvimento e da consideração de toda a perversidade do sistema capitalista, há de se considerar que todo esse processo de reestruturação territorial-produtiva que tem acometido a região de estudo tem sido fundamental em fomentar novas expectativas, possibilidades e potencialidades para a cidade; mas, para que se possa aproveitar deste panorama até então otimista, tem que se preocupar com a gestão, com um planejamento e a criação de infraestruturas adequadas por meio de políticas públicas. Todas estas novas formas de organização são responsáveis pelo desenvolvimento da cidade, que tem feito surgir essa "Nova Itaguaî"; mas não basta uma "nova roupagem", sendo de extrema importância tanto a manutenção do desenvolvimento da economia brasileira a nível global quanto a maior democratização dos resultados deste crescimento ainda eminentemente produtivo.

Portanto, o processo de reestruturação territorial-produtiva tanto representa uma "caixa de surpresas" para a cidade de Itaguaí, com uma miríade de dúvidas e incertezas quanto gera alguns expectativa sobre a potencialidade do desenvolvimento para a região. A questão é a discussão do que é esse desenvolvimento para Itaguaí e a luta por esse desenvolvimento: Como? Para quem? Até quando? São perguntas que requerem respostas urgentes.

\section{BIBLIOGRAFIA}

FILHO, Júlio C. G. O Arco Rodoviário Metropolitano como Elemento de Reestruturação do Espaço Fluminense. Revista Continentes: Revista de Geografia da UFRRJ, ano 2, n.2, 2013. Disponível em: http://r1.ufrrj.br/revistaconti/pdfs/2/ART7.pdf. Último acesso em: 10 de maio de 2015.

FIRJAN, Estudos para o desenvolvimento do Estado do Rio de Janeiro. Avaliação dos impactos logísticos e socioeconômicos da implantação do Arco Metropolitano do Rio de Janeiro. Edição n³, 2008.

GOMES, Maria Terezinha Serafim. O Debate sobre a Reestruturação Produtiva no Brasil. In: RÁE GA 21 (2011), p. 51-77. Curitiba, Departamento de Geografia, UFPR. Disponível em www.ser.ufpr.br/raega. Acesso em 10 de dezembro de 2013

LEFEBVRE, H. O Direito à Cidade. São Paulo: Centauro, 2001.

LENCIONI, S.. Reestruturação: uma noção fundamental para os estudos transformações e dinâmicas metropolitanas. In: Encontro de Geógrafos da América Latina. VI, Buenos Aires, Universidade de Buenos Aires, 1998. Anais... Buenos Aires, Universidade de Buenos Aires, 1998, p.1-10.

LIMA. I. G; ROCHA, A. S. Expressão Geopolítica da Baixada Fluminense: os trunfos de legitimidade territorial em jogo. In: Anais XVI Encontro Nacional de Geógrafos. Crise, práxis e autonomia: espaços de resistência e de esperanças. AGB: Porto Alegre, 2010.

MULS, L. M. O desenvolvimento econômico local do município de Itaguaí: o capital social e o papel das micro, pequenas e médias. Rio de Janeiro: Imprensa UFRJ, 2004. 
OLIVEIRA, Floriano José Godinho de. Reestruturação Produtiva e Regionalização da Economia no Território Fluminense, 2003. Tese (Doutorado em Geografia Humana). Departamento de Geografia da Faculdade de Filosofia, Letras e Ciências Humanas, Universidade de São Paulo, São Paulo, 2003.

OLIVEIRA, Leandro Dias de. A Construção do Desenvolvimento Sustentável na Cidade de Volta Redonda: Um Estudo sobre Reestruturação do Território e Ideologia, 2006. 204 p. Dissertação (Mestrado em Geografia) - Departamento de Geografia, Universidade do Estado do Rio de Janeiro (UERJ), Rio de Janeiro, 2006.

OLIVEIRA, Leandro Dias de. A Geopolítica do Desenvolvimento Sustentável: um estudo sobre a Conferência do Rio de Janeiro (Rio - 92), 2011. 283 p. Tese (Doutorado em Geografia) - Instituto de Geociências, Universidade Estadual de Campinas (UNICAMP), Campinas - SP, 2011.

OLIVEIRA, Leandro Dias de. Os desafios do ensino de geografia em tempos de reestruturação territorial-produtiva da cidade de Seropédica. In: GRANHA, Gustavo Souto Perdigão; FAzOLLO, Sara Araújo Brito; MORAES, Francisco José Dias de; SILVA, Wanderley da; JORGE, Vladimyr Lombardo (Orgs.). O PIBID da UFRRJ: formação docente e práticas pedagógicas inovadoras em sala de aula. Rio de Janeiro: Imperial Novo Milênio, 2015.

PEREIRA, Regina Celi. Estado, território e reestruturação produtiva na metropóle fluminense. Espaço e Economia [Online], 3 | 2013. Disponível em: http://espacoeconomia.revues.org/390. Último acesso em: 10 de maio de 2015.

\section{NOTAS}

1. Tal termo é fruto dos debates realizados no âmbito das reuniões da linha de pesquisa Reestruturação Espacial Contemporânea, com liderança do Prof. Dr. Leandro Dias de Oliveira.

\section{RESUMOS}

Área historicamente marcada por forte exclusão econômica e social, Itaguaí tornou-se um verdadeiro pólo econômico devido aos grandes investimentos do ramo industrial-produtivo (metal-siderúrgico) e logístico-portuário. Ocorrido no âmago de uma profunda reestruturação territorial-produtiva, tal processo faz com que o município de Itaguaí, localizado na Região do Extremo Oeste Metropolitano Fluminense, assuma novas formas, modelos e funções econômicoespaciais. Nesse sentido, a intenção do presente artigo é analisar as modificações econômicas em curso em Itaguaí.

Itaguaí, an area historically characterized by strong economic and social exclusion, has become an economic center due to large investments in the industrial-productive sector (metal and steel) and port logistics. This process, occurred at the heart of a deep-territorial restructuring process, makes the city of Itaguaí, located in Rio de Janeiro state's west end metropolitan area, assume new forms, models and economic and spatial roles. Therefore, the intention of this paper is to analyze the ongoing economic changes in Itaguaí. 
En s'agissant d'un espace marquée d'une forte exclusion économique et sociale, Itaguaí est devenu un vrai pôle économique grâce aux investissements industriels (métallurgie et sidérurgie) et logistiques (le Port d'Itaguaí). A l'intérieure d'une profonde restructuration territoriale et productive, ce processus est responsable de la création de nouvelles formes, fonctions et modèles économiques et spatiales. Ainsi, cet article a l'intention d'analyser les changements économiques en cours dans la municipalité d'Itaguaí, située dans la région extrême-ouest de la métropole fluminense.

Situada en un área históricamente marcada por la exclusión económica y social, Itagüí se convirtió en un verdadero polo de desarrollo económico, debido a las grandes inversiones del conglomerado industrial, siderúrgico y portuario en la ciudad. La propuesta es, analizar las modificaciones económicas que se encuentran en curso en la ciudad de Itaguaí, situada en la Región del Extremo Oeste Metropolitano Fluminense, que vive un proceso de reestructuración territorial - productiva, con nuevos locales, formas, modelos y funciones económicas y espaciales.

\section{ÍNDICE}

Mots-clés: restructuration territoriale et productive, Itaguaí, région métropolitaine fluminense, développement économique, port d'Itaguaí.

Palavras-chave: reestruturação territorial-produtiva, Itaguaí, Região Metropolitana Fluminense, desenvolvimento econômico, Porto de Itaguaí.

Palabras claves: reestructuración territorial - productiva, Itaguaí, Región del Extremo Oeste Metropolitano Fluminense, desarrollo económico, Puerto de Itaguaí.

Keywords: territorial-productive restructuring, Itaguaí, Rio de Janeiro state's metropolitan area, economic development, Port of Itaguaí.

\section{AUTOR}

GUILHERME MAPELLI CHAGAS 